issues live up to this assessment: in addition to articles on mice, fruitflies, zebrafish and the roundworm Caenorhabditis elegans, we find interesting papers on amphioxus, pigs, turtles and the marine ciliate Euplotes crassus.

Of course, there are other journals that cover developmental genetics, such as Development, Mechanisms of Development or Development, Genes and Evolution. However, Genesis seems well positioned in this journalistic ecosystem. An interesting feature is the "Technology Reports". These cover topics such as the latest tricks for gene targeting in mice or gene silencing in flies, as well as explaining the relevance of the Swiss-Prot database to developmental research - from the sequence of nucleotides to the sequence of pathways.

Genesis seems to have the mix of ingredients required for survival among journals of functional genomics: dedicated editors, rapid publication and an anticipation of the direction of an emerging field. I am sure I will revisit many of the articles I read - some of them to help my students design experiments, some to help me take advantage of the power of the comparative approach.

The editors encourage researchers studying "non-traditional" organisms to submit their papers to Genesis. I encourage those with a curiosity in the latest developments in functional genomics to look into the journal.

http://www.interscience.wiley.com/jpages/1526-954X

Rudi Balling is at the Institut für Säugetiergenetik, GSF-Forschungszentrum für Umwelt und Gesundheit, Ingolstädter Landstrasse 1, 85758 Neuherberg, Germany.

\section{Psychic secretions}

\section{The International Journal of Neuropsychopharmacology \\ editor-in-chief B. Lerer \\ Cambridge University Press. 4/yr. $£ 112$

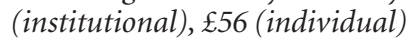

\section{John C. Marshall}

It was a slow journey from the Hippocratic humours (black bile, phlegm, blood and yellow bile) to Otto Loewi's 1924 discovery that synaptic transmission from the vagus nerve to the heart muscle was chemically controlled - the first of many neurotransmitter substances (acetylcholine) had been found.

A slightly longer and more tortuous journey led to the conjecture that too much or too little of various neurotransmitters and other neuroactive chemicals was implicated in many neurological and psychiatric dis- eases. This was reinforced by the development of animal models of these diseases. The upshot was the emergence of a new discipline - neuropsychopharmacology that gave substance to the claims of PierreJean-Georges Cabanis, an eighteenth-century physician and ideologue, who had notoriously argued that the brain digests impressions and secretes thought.

The International Journal of Neuropsychopharmacology covers the entire range of topics that plausibly fall within the domain of its title. A fairly rapid publication schedule combined with high-quality papers make this journal essential reading for all basic and clinical scientists concerned with the biochemistry of the nervous system in health and disease. Thus far, the largest number of research papers in the journal deal with the biochemistry of major depression and schizophrenia. But the wider scope of neuropsychopharmacology is reflected in contributions on movement disorders, mania, anxiety, aggression and pain.

Discussion is facilitated by excellent review articles and a timely trends and perspectives section. The latter feature has included a fine exposition of the health implications of cannabis consumption. Relevant aspects of molecular genetics are also well covered, including a running review of the uses of knockout mice (although neuroscientists who are puzzled by how studies of rats can illuminate schizophrenia will doubtless remain so).

Watch this space. As the editorial team write in their introduction to the journal: "tenets held basic to contemporary neuropsychopharmacology could turn out to be substantially overemphasized, unacceptably simplistic or even incorrect, in the relatively near future."

\section{http://www.journals.cup.org/owa_dba/owa/} ISSUES_IN_JOURNAL?JID=PNP

John C. Marshall is at the Neuropsychology Unit, University Department of Clinical Neurology, Radcliffe Infirmary, Oxford OX2 6HE, UK.

\section{Problems of a glandular nature}

\section{Pituitary}

editor-in-chief Shlomo Melmed

Kluwer. 4/yr. \$314 (institutional), \$100 (individual)

\section{Stafford L. Lightman}

The editorial board includes some of the best-known international figures working on the pituitary gland - clinical endocrinologists, neurosurgeons, molecular biologists, neuroendocrinologists and pituitary histopathologists. Pituitary is aimed at all areas of hypothalamic-pituitary function, from the most fundamental cell biology through to clinical case reports.

The journal must have given its editors considerable problems. There are already many journals covering clinical endocrinology, neuroendocrinology and neurosurgery, so it was important for them to carve out a niche that would serve a population of clini$\mathrm{cal}$ and basic scientists. They have sought to do this by dividing the journal into sections devoted to basic research, clinical studies and reviews, with occasional 'portraits' of recent congresses or other newsworthy events.

Pituitary itself is nicely presented, with good quality print, although some of the plates of immuno-stains lack clarity. The editors have clearly had a struggle to attract the high-quality manuscripts the journal deserves, and this may reflect the catch-22 situation of awaiting cover by the citation and abstracting agencies.

There are interesting papers at the clinico-pathological interface, which could be the journal's greatest strength. It is, however, noticeable that although the initial volumes had quite a large basic science content, this seems to have diminished in later issues, and although the journal is published only four times a year, the most recent volume in May

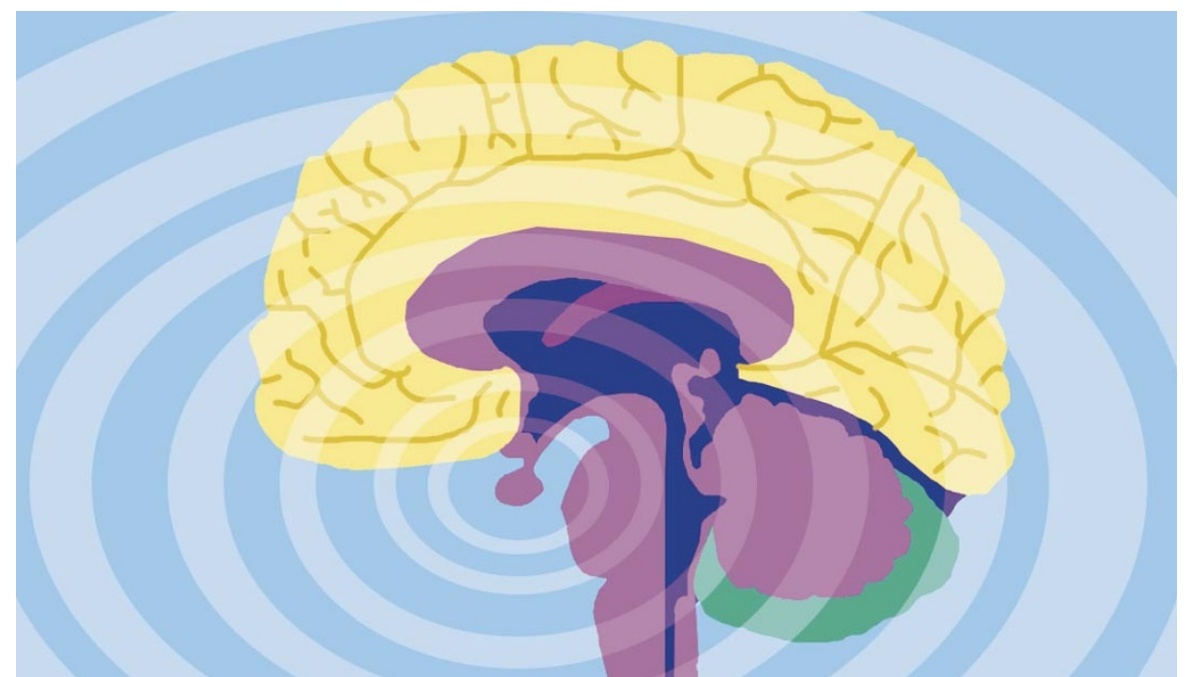


2000 is only 50 pages long, has two basic science papers and five clinical articles, of which three are case reports.

The scientific and clinical excellence of the editors puts them in a good position to attract the high-quality manuscripts essential to making this journal a success. At present they have their work cut out for them.

http://www.wkap.nl/journalhome.htm/1386-341X Stafford L. Lightman is in the Department of Medicine, University of Bristol, Bristol Royal Infirmary, Bristol BS2 8HW, UK.

\section{The art of the}

\section{saveable}

\section{Animal Conservation}

editors Michael W. Bruford,

John L. Gittleman, Georgina M. Mace

\& Robert K. Wayne

Cambridge University Press. 4/yr. £89, \$145

(institutional), £41, $\$ 69$ (individual),

$\mathfrak{E} 19, \$ 31$ (student)

\section{William J. Sutherland}

If politics is the art of the possible and science the art of the soluble, then conservation is surely the art of the saveable. The widespread concern over local and global environmental change has produced an outburst of interest among students, a redirection of ecological research towards applied questions and an expanding community of conservation biologists.

Animal Conservation is a very welcome contribution to the art. It covers the spectrum of conservation science (with a particular strength in evolution and genetics) and balances practicalities with fundamental issues. Thus the latest issue includes the genetic management of chondrodystrophy in California condors, whether fluctuating asymmetry can be used to detect inbreeding in endangered species, a protocol for re-establishing the beaver in Scotland and using human densities to interpret declines of large carnivores. The contents are usually so interesting and topical that I find myself reading most of the journal, and the students on our MSc course in conservation biology successfully petitioned our librarian to start subscribing!

Animal Conservation focuses on conservation science and excludes associated subjects such as policy and education. It is thus more narrow in scope than the market leader, Conservation Biology. The restriction to animals seems somewhat old-fashioned, especially as so many concepts apply equally to the rest of biodiversity; general papers on communities, biodiversity and ecosystem processes are likely to be submitted elsewhere.

The journal has started well. Even the first

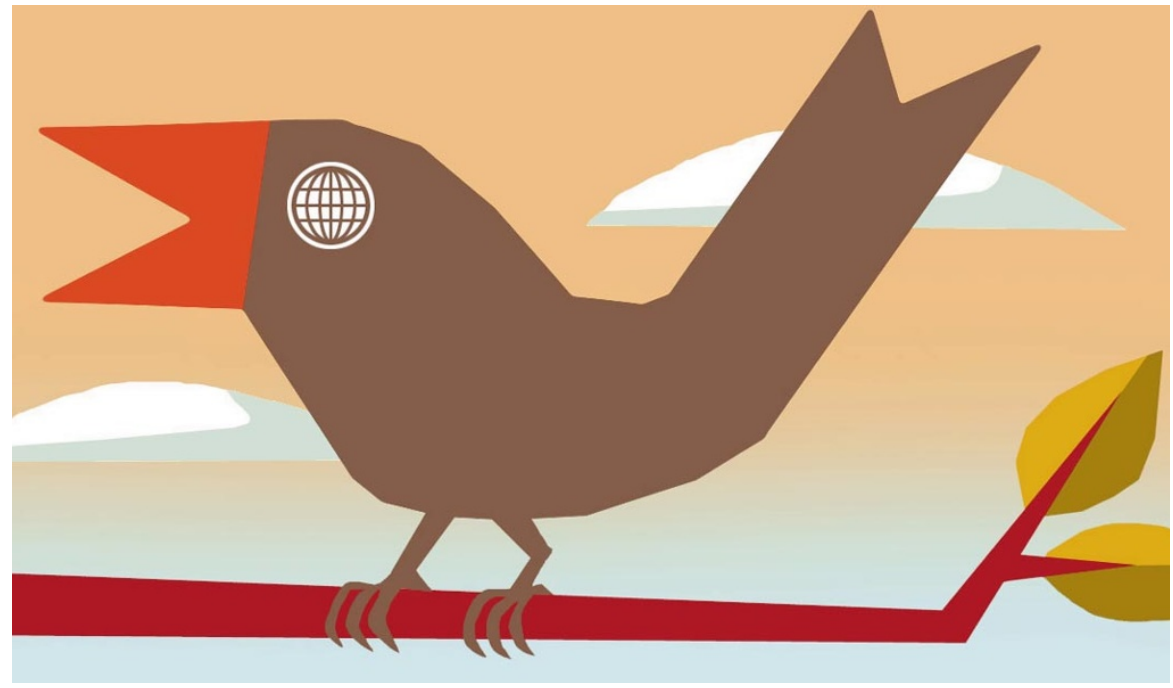

issue contained a series of interesting papers, and this quality has been maintained. Animal Conservation has the potential to become the major conservation science journal within a few years.

\section{http://uk.cambridge.org/journals/ani}

William J. Sutherland is at the School of Biological Sciences, University of East Anglia, Norwich NR4 7TJ, UK.

\section{Strong growth in the environmental field}

\section{Journal of Environmental \\ Monitoring}

editor Harp Minhas

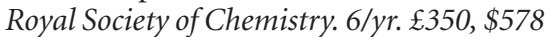

(institutional), $£ 60, \$ 96$ (individual)

\section{Journal of Environmental Policy}

\section{\& Planning}

editors Kevin Bishop, Andrew Flynn

\& Terry Marsden

Wiley. 4/yr. \$190 (institutional), \$105 (individual)

\section{Graham Wood}

Environmental monitoring and the implementation of informed and effective environmental policies are essential components of any initiative that attempts to grasp the illusive Holy Grail of sustainable development. Continued growth in the status of environmental issues seems unquestionable, and a huge diversity of research activity now exists that could come under the environmental umbrella. The inherent interdisciplinary nature of environmental research means that material in an emerging sub-discipline has a tendency to be scattered among a plethora of journals. Reflecting the natural-science and socialscience traditions respectively, the Journal of Environmental Monitoring (JEM) and the
Journal of Environmental Policy \& Planning (JEPP) both seek to provide a single coherent outlet for research within their individual evolving fields.

Published by the Royal Society of Chemistry, JEM focuses on all aspects of the measurement of chemical, physical and biological agents indoors, outdoors and in the workplace. The emphasis of the journal is on exposure assessment in relation to adverse environmental and health effects. To date, the journal has published contributions from a diverse international group of writers, featuring a good-quality mix of long and short research articles, many derived from programmes funded by national research councils, the European Commission and major industrial sponsors. Production quality is high and the journal can boast an impressive turnaround time, with an average duration between submission and publication of just four months. In addition to research papers, JEM incorporates a variety of short, magazine-style scientific articles covering topical issues of general interest, and a useful news section that often includes web links to further information. All in all, $J E M$ is a well-rounded periodical that has got off to a good start in its first year.

$J E P P$ aims to provide "a forum for critical analysis" in the field, a key theme being to facilitate integration of different communities (including academics and policy-makers), different policy sectors and spatial scales, from local through to global. The journal is primarily, though not exclusively, concerned with Europe and has attracted a range of good-quality articles. It covers a variety of theoretical and empirical studies. A useful feature is the "progress report" in each issue, which has either a thematic or a regional focus. It is a healthy sign that the stated aims and scope of the journal, and although submission-to-acceptance times are painfully slow, they are not atypical (five to 18 months, with a further publication lag editors have not strayed from the originally 